\title{
Training as a Factor Influencing Adoption of Innovations along Mango Value Chains in Meru County, Kenya
}

\author{
Isaiah Gitonga Imaita ${ }^{1}$ \\ ${ }^{1}$ School of Business Administration, Mount. Kenya University, Kenya \\ Correspondence: Isaiah Gitonga Imaita, School of Business Administration, Mount. Kenya University, Kenya. \\ E-mail: iimaita@yahoo.com
}

Received: January 8, 2013 Accepted: January 30, 2013 Online Published: February 28, 2013

doi:10.5539/ijms.v5n2p74 URL: http://dx.doi.org/10.5539/ijms.v5n2p74

\begin{abstract}
The study has used a descriptive survey design. The study was carried out in Meru County. The study area was limited to the lower part of Meru County whose climatic condition is suitable for mangoes production. This study adopted a likelihoodselection method for getting the respondents. Out of 13,442 farmers, traders and exporters, 447 farmers, 12 traders and 2 exporters were randomly selected for interview. Secondary data used in the study was collected from the Ministry of Agriculture Offices. To ensure validity and reliabity questionnaires were pretested and the researcher supervised data collection. Quantitative data obtained from the field was analyzed using descriptive and inferential techniques. The descriptive techniques adopted were means and frequencies while the inferential technique used were regression and correlation to establish relationship between variables in the study and inferences made. Frequency tables and charts were used to present the findings.

The study found out that lack of training was an hindrance in innovation adoption. The more the training the more the adoption of innovation.Chi-square results show that training has a significant association with innovation in Mango value chain as shown by a value of 39.139 at $(\mathrm{p} \leq 0.05)$.

The researcher concludes that lack of organizations/institutions support has also undermined innovation adoption in mango supply chain. There is need to establish good linkages between farmers and research development systems which offer training on new technologies or innovations as well as assisting farmers in accessing markets for their products.
\end{abstract}

Keywords: value chain, training, agriculture, mango, adoption, innovation

\section{Introduction}

About $80 \%$ of the population live in rural areas and thrive on farming. The growth in agriculture has been on the decline in recent years. This has affected fruit farming in the country, which has also continued to decline just as the country's general economy (World Bank, 2007). The Government of Kenya has put in place and proposed a strategy for revitalizing agriculture, $2004-2014$ with the aim of raising the sector's growth rate, reduction of unemployment and poverty. This revitalizing agriculture strategy aims at achieving the country's Millennium Development goal of Poverty Reduction (Horticulture Crop Development Authority, 2008).

However, the agricultural sector continues to face major challenges affecting the value chain mostlyowing to lowproduction, inefficient land utilization, poor marketing system, and lack of adding value. The problems are aggravated by the hostilerecognizedstructures currently prevailing the country (Moturi et al., 2010).

The government through "Vision 2030" has come up the following initiatives; strengthening agricultural extension which is aimed at encouraging farmers to produce products for local and international markets, encouraging and supporting rural industries, encouraging and supporting irrigation in arid and semiarid areas and better management the arable land(Republic of Kenya, 2008). These initiatives will go a long way in strengthening the adoption of innovations along the mango value chain.

According to the ROK (2009), value chain analysis can strengthen the innovation process by determining the contribution of each actor with a view to maximizing synergies and complementarities between actors.

According to Diederen, et al, 2002, agricultural progress is driven by technological innovations. The impact of innovations is determined by the extent to which farmers adopt available innovations and the speed by which 
they take up the innovations. Farmers don't adopt innovations all at once. There are those who have wait and see attitude and there are those who are get goer.

Despite them being successful, the agricultural revolution is still dynamic and calls for new innovation systems on a constant basis (World Bank, 2006).

Speedy technological progress in low developing countries is inhibited by deficient credit system, lack of data, abhorrence to hazards, lack of proper land policy, unsatisfactory human resource, lack of farm machinery, lack of appropriate farm inputs and unsuitable means of communication Rezvanfar, (2007).

\section{Problem Statement}

For the last forty years during mangoes harvesting season, the researcher has observed that a lot $(39 \%)$ of mangoes in MeruCounty go to waste. This is also emphasized by DANIDA report (2010). However, technologies (innovations) exist to arrest this situation but farmers are yet to adopt these innovations.

Some of the innovations include: grafting of the indigenous varieties so that varieties which are marketable can be produced (HCDA, 2006), parasitic wasp and a combination of other Integrated Pest Management (IPM) techniques to control fruit flies which cause great damage to the mango fruit and thus give confidence to the market (Ejidiah, 2010), processing of mangoes like it is done in India by Coca Cola (mixing mangoes and milk) (Best Media Info Bureau, 2010). According to FAO, training of farmers on agronomy and animal production, and farm management are keys to value chain development. Studies by Mussei et al. (2001) in Tanzania, Getahun et al. (2000) in Ethiopia and Abd El-Razek (2002) found factors such as financial resources and training influenced technology adoption.

This study therefore sought to find out whether training influences the adoption of innovations along the mango value chain in Meru county and consequently in Kenya.

The objective of this study was to establish the role trainingplays in adoption of innovations along the mango value chain in Meru County.

\section{Research Hypothesis}

$\mathrm{H}_{0}$ : Training is not associated with innovation, and

$\mathrm{H}_{1}$ : Training is associated with innovation.

\section{Review of Related Literature}

The Ministry of agriculture is the principal institution setting agricultural policy and planning and carrying out agricultural development programs to assist farmers in production (ROK, 2009). According to Feder and Slade (2004), training to farmers is mostly through agricultural officials such as extension/field officers or through veterinary officers. The knowledge the farmers get through training makes them learn internalize, evaluate, try and adopt new technologies (Caswell et al., 2001). However, Feder and Slade (2004) indicates that, the extension agents must be knowledgeable about the information they intend to impart to the farmers otherwise if the farmers realize the information is not clear and credible they will reject it like they rejected the new technology in dairy production Lemma and Trivedi. (2012).

Feder and Slade (2004) assert that for the new technology to be adopted, the farmers must be sure it works and it has been tried elsewhere.

Rogers (2005) after reviewing 156 studies had generalized that "Earlier adopters have more change agent contact than later adopters", since $87 \%$ of all the studies he reviewed supported such a generalization. Other studies as well show that there is significant association related to up take of technologies and extension contact. Examples of these studies were Musseiet al. (2001), Getahun et al. (2000), Baidu Forson (2000), Madhukar and Ram (2012) and Abd El-Razek (2002). However some studies found no relationship between the two variables. Examples of these studies were Bulale (2000), Salama (2001), and Adesina Baidu-Forson (2005).

Significant association related to up take of technologies and veterinarian contact has been reported by majority of studies. Examples of these studies were, Salama 2001, El-Melegi (2000)).

Msabeni, et al; (2010) carried out a study on mango marketing system in Mbeere county in Kenya. They found out thatthe marketing system was weak because it was not efficient in delivering the products to the end users. The farmers lacked credible market information which would facilitate them make quick decisions. The extension officers lacked credible market information and so were unable to give up to date timely information. Traders who had timely information took advantage of the situation. This calls for a concerted effort to improve the information system for the betterment of all stakeholders in the system (HCDA, 2008). 


\section{Research Methodology}

This research was guided by the methodology used by Nchinda and Mendi (2008) in the study done in Cameroon on adoption of innovation in the dairy sector.

\subsection{Research Design}

This study assumed participatory action when pretesting and administering the Questionnaires. Baseline survey was done. To ensure validity and reliability, the researcher supervised the data collection.

The study districts included the former Meru Central and Meru North Districts currently known as Meru County. The County lies to the east of Mt. Kenya whose peak cuts through the southwest border of the County. To the North East it borders Laikipia County, to the West it borders Nyeri and Kirinyaga counties, Tharaka Nithi county in the south and Isiolo county to the north.

\subsection{Participant (Subject) Characteristics}

The study was concentrated on seven divisions, which are highly productive in mangoes as shown in Table 1 .

Table 1. Study areas (survey figures, 2010)

\begin{tabular}{llllll}
\hline Meru County & STUDY & AREA UNDER & PRODUCTION IN & $\begin{array}{l}\text { NUMBER OF } \\
\text { FARMERS }\end{array}$ & $\begin{array}{l}\text { Sample } \\
\text { size }\end{array}$ \\
& DIVISIONS & MANGO per Ha. & MT (2010) & 910 & 30 \\
& Imenti North & 275 & $2,586.97$ & 4,347 & 144 \\
& Meru Central & 1289 & $14,553.97$ & 516 & 17 \\
& Imenti South & 73 & $1,011.11$ & 4,023 & 134 \\
& Igembe South & 278 & $3,120.14$ & 2,176 & 72 \\
& Igembe North & 71 & 637.37 & 1,074 & 36 \\
& Tigania West & 106 & 783.06 & 396 & 14 \\
Total & Tigania East & 31 & 170.34 & $\mathbf{1 3 , 4 4 2}$ & $\mathbf{4 4 7}$ \\
\hline
\end{tabular}

Source: MOA, 2010

The study area was limited to the lower part of the County whose climatic condition favors the production of mangoes. The population of the study included individual mango farmers, traders and exporters in Meru County. The mango farmers are approximately to be 13,442, traders are 120, while exporters were 12 (MOA Survey, 2000). Therefore, the target population for the study was 13,574 traders, farmers and exporters.

\subsection{Sampling Technique}

The Population of Mango farmers in the county was estimated at 13,454 . Since the population is large (above 10,000 ), the following formula was adopted to calculate the sample size of farmers.

$$
n=\frac{N}{[1+N e 2]}
$$

A sample size of 447 mango farmers/ growers was established.

Non probability sampling method was used to get a sample size of traders and exporters since the target population was not homogeneous. The researcher therefore sub-divided it into groups or strata in order to obtain a representative sample. From the above population of thirteen thousand five hundred and seventy four, $10 \%$ from both traders and exporters, giving each item in the population an equal probability of being selected. This generated a sample size of 461 respondents from whom the study sought information. Table 2 below gives summary of the sample size.

Table 2. Sample size (MOA, 2010)

\begin{tabular}{llll}
\hline Sections & Population (Frequency) (N) & Sample Ratio & Sample (n) \\
\hline Traders & 120 & 0.1 & 12 \\
Exporter & 12 & 0.1 & 2 \\
Total & $\mathbf{1 3 , 5 7 4}$ & & $\mathbf{1 4}$ \\
\hline
\end{tabular}


The questionnaires were then distributed through the ministry's division headquarters. Out of the target population, 447 questionnaires were administered to 447 farmers, 12 traders and 2 exporters. Out of the 418 questionnaires distributed, 296 questionnaires were returned with 283 coming from farmers, 12 from traders and one from an exporter.

\subsection{Measures and Covariates}

Primary data (mainly information on factors influencing adoption) were collected from the respondents through questionnaires. Structured questionnaire with both open and close ended questions were the key instruments used in collecting primary data from the respondents. The questionnaire was pre-tested before being administered to the respondents.

Quantitative data obtained from the field was coded using the SPSS and analyzed using descriptive and inferential techniques. Descriptive techniques were adopted using frequencies to show the tendency of occurrence between study variables. Inferential techniques like regressions were used so as to establish the relationship between variables in the study and inferences made.

A logit analysis was used to determine whether adoption of innovation was influenced by training. Similar model was used by Nchinda and Mendi, (2008) to investigate the adoption of innovation in the dairy sector in Cameroon. The model was conducted by transforming 'innovation adoption' variable into binary $(1=$ adopted innovation, $0=$ has not adopted innovation). Logit regression was preferred as it is not affected by other factors such as serial autocorrelations and would, thus, have a better presentation of the prediction. Innovation (I) was the dependent variable while training $(\mathrm{X} 1)$, was the independent variable. The variable was measured based on the respondents' agreement or disagreement with the variable indicators whereby agreement was accorded $1=$ adopted innovation, $0=$ has not adopted innovation.

The study was done on the independent variable as shown below:

$$
P\left(Y=1 \mid X_{1}, \ldots, X_{p}\right)=\frac{e^{=+\sum_{j=1}^{\infty} \theta_{j} X_{1}}}{1+e^{=+\sum_{j=1}^{\infty} \theta_{1} X_{1}}}
$$

Where: $\mathrm{Y}=$ the dependents variable (Adaptation of mongo technology)

$\mathrm{Xi}=$ Independent Variable (Training: $0=$ not adopted, $1=$ adopted)

$\alpha=$ Constants

$\beta \mathrm{j}=$ parameter estimates corresponding to $\mathrm{Xj}$ 's.

$e=$ exponential $($ constant $=2.71)$

\section{Results}

The study found out that majority (69\%) of the mango growers in Meru County were trained on agronomy, while $31 \%$ were not trained. Out of the trained growers, $76.5 \%$ adopted innovations and $23.5 \%$ did not adopt. Out of the untrained growers, $1315 \%$ adopted innovations and 74 85\% did not adopt innovations. The growers indicated that the untrained learnt from their neighbors.

Inregard to training on marketing, $63.3 \%$ of growers indicated that they were trained on marketing, $36.7 \%$ indicated that they were not trained. Out of the trained growers, $49 \%$ adopted innovations and $51 \%$ did not adopt. Out of the growers who were not trained, $6.7 \%$ adopted innovations and $93.3 \%$ did not adopt.

Training on processing, it was found out that only $8.8 \%$ of growers were trained on mango processing while, $91.2 \%$ were not trained. Out of the trained growers, $8 \%$ adopted innovations and $92 \%$ did not adopt the innovations. Out of the untrained growers, $1 \%$ adopted innovation and $99 \%$ did not adopt the innovation. This means there was less training on processing.

On training for traders, the study found out that $38.5 \%$ trader/exporter were trained on agronomy while, $61.5 \%$ were not trained. Out of the trained traders/exporters, $40 \%$ adopted the innovation and $60 \%$ did not adopt. Out of the untrained, $13 \%$ adopted the innovation and $87 \%$ did not adopt the innovation.

The study found out that $84.6 \%$ of traders/exporters were trained on marketing while $15.4 \%$ were untrained. Out of the trained traders/exporters, $73 \%$ adopted marketing innovations but $60 \%$ out of the trained traders/exporters did not adopt innovations. Out of traders/exporters that were untrained, $50 \%$ adopted marketing innovations and $50 \%$ did not adopt innovations. Growers had low $8 \%$ marketing adoption rate for the trained and $1 \%$ for the untrained while traders/exporters had $73 \%$ marketing adoption rate for the trained and $33 \%$ for the untrained. 
The study also sought to establish whether traders/exporters were trained on processing and the results were that $10(76.9 \%)$ were trained and $3(23.1 \%)$ were not trained. Out of the trained traders/exporters, $3(10 \%)$ adopted processing innovations and $7(70 \%)$ did not adopt the innovations. Similarly, Out of the untrained trader/exporter, $1(33 \%)$ adopted processing innovations and 2(67\%) did not adopt the innovations. The analysis, thus, reveals that training influences innovation adoption. Grower processing adoption rate was lower (8\%) for the trained and $1 \%$ for the untrained compared to traders/exporters whose adoption rate is $30 \%$ for the trained and $33 \%$ for the untrained. The researcher can therefore conclude training influences innovation adoption since majority of the trained mango growers and traders adopted innovations to a high extent as compared to the untrained.

\subsection{Logit Regression Results}

Table 3. Logit model coefficients

\begin{tabular}{llllllll}
\hline & & B & S.E. & Wald & Df & Sig. & Exp(B) \\
\hline Model 1: Grower & Training & .319 & .306 & 1.082 & 1 & .298 & 1.375 \\
\cline { 2 - 8 } & Constant & -1.148 & .776 & 2.187 & 1 & .139 & .317 \\
\hline Model 2: Traders/ & Training & 19.817 & 23210 & 0 & 1 & 0.999 & $4.04 \mathrm{E}+08$ \\
\cline { 2 - 8 } Exporters & Constant & 42.365 & 57340 & 0 & 1 & 0.999 & $2.51 \mathrm{E}+18$ \\
\hline
\end{tabular}

Note: Variable(s) entered on step1: Marketing Skills and Training.

That study shows that training would lead to a 0.319 increase in innovation adoption.

The Logit model shows that, when other factors are held constant, training would increase the same by 19.817 .

\subsection{Chi-Square Results}

Chi-square test was used to determine whether an association (or relationship) between independent and dependent variable in the sample is likely to reflect a real association in the population. The null and alternative hypotheses for the chi-square test were:

\section{Hypothesis}

$\mathrm{H}_{0}$ : Training is not associated with innovation, and

$\mathrm{H}_{1}$ : Training is associated with innovation.

Table 14. Chi-square - innovation and independent variable

\begin{tabular}{|c|c|c|c|c|c|}
\hline & & & Value & $\begin{array}{l}\text { Degrees of } \\
\text { Freedom (df) }\end{array}$ & $\begin{array}{l}\text { Asymp. } \\
\text { Sig. } \\
\text { (2-sided) }\end{array}$ \\
\hline \multirow{3}{*}{ Model 1} & \multirow{3}{*}{ Training } & Pearson Chi-Square & $39.139 d$ & 20 & .006 \\
\hline & & Likelihood Ratio & 41.166 & 20 & .004 \\
\hline & & Linear-by-Linear Association & .010 & 1 & .920 \\
\hline \multirow{3}{*}{ Model 2} & \multirow{3}{*}{ Training } & Pearson Chi-Square & 14.300 & 6 & .026 \\
\hline & & Likelihood Ratio & 17.323 & 6 & .008 \\
\hline & & Linear-by-Linear Association & .672 & 1 & .412 \\
\hline
\end{tabular}

Chi square results on growers shows that, a chi-square value of 39.139 was established at $\mathrm{p}=0.006(\mathrm{p}<0.05)$ on training. The null hypothesis is thus rejected and alternative hypothesis accepted. However, a linear by linear association was found to be insignificant at $\mathrm{p}=0.920(\mathrm{p}>0.05)$.

In traders/exporters perspectives; on training, a chi-square value of 14.300 was established at $\mathrm{p}=0.026(\mathrm{p}<0.05)$. However, a linear by linear association was found to be insignificant at $\mathrm{p}=0.412(\mathrm{p}>0.05)$.

\section{Discussion}

The study further sought to establish whether training influences innovation adoption. Formal education was a factor in innovation adoption. The survey found out that the growers who attained primary education (14.4\%) had higher innovation adoption rate than those who did not have any education at all (3.9\%). This is in line with 
Ronson (2007) and Nchinda and Mendi(2008), who established that education was a factor influencing adoption of innovation.

It was established that $69 \%$ of growers and $38.5 \%$ of traders/exporters were trained on agronomy, and their adoption rate was $57.6 \%$ and $23 \%$ respectively. That is why production was not a major problem. The major problem observed was marketing and processing. Although $63.3 \%$ growers and $84.6 \%$ traders/exporters were trained on marketing, only $33.6 \%$ of growers, and $69.3 \%$ of traders/exporters adopted marketing innovations. This explains why traders/exporters could make better informed decisions than growers. The findings also reveal that out of $8.8 \%$ of growers and $76.9 \%$ of traders/exporters, who were trained on processing, $1.4 \%$ growers, and $30.9 \%$ traders/exporters adopted processing. This also explains why there were very few new ventures. The study established that there was only one group which was in the process of starting a processing plant. This indicates that training influences innovation adoption.

According to Caswell et al., 2001, acquisition of information about a new technology entices them to try and adopt the technology. This explains why majority of the growers had higher $(76.5 \%)$ agronomy adoption rate than trader/exporter whose adoption was $40 \%$ for the trained. Agronomy as a technology is more applicable to farmers than to traders; this explains why farmers who had adopted agronomy were more than the traders.

\section{Conclusion}

Lack of organizations/institutions support has also undermined innovation adoption in mango supply chain; Organizations would have been established as the best linkages between farmers and innovations and the research and development systems.Organizations would also help develop innovation programs creating a communication channel between governments, farmers and development of agricultural projects. They could equally take various roles in the mango supply chain including, offering trainings to farmers on farming practices, enlightening farmers on new technologies or innovations as well as assisting farmers in accessing markets for their products.

On theinfluence of training on innovation adoption, the findings show that there was low training on processing. This shows that there should be deliberate attempts by the Ministry of Industries (Strategic plan 2010/2015) to come up with business incubation program targeting counties to facilitate local processing for the local and international markets. This can only succeed if it is backed by policy framework enacted by the same Ministry through treasury to give tax holiday for those investors who put processing ventures into the rural areas on condition that they use $65 \%$ locally produced raw materials. At the same time, in order for this to succeed, there should be deliberate policy framework enacted by the government to protect local industries through enactment of high tariff to bar similar competing goods. The incoming goods should pay high tax making them be sold at high prices in the local market. This would facilitate wealth and job creation.

The study recommends intensification of training by value chain members and stakeholders, that is the Ministry of Agriculture, NGOs and private sector on the areas of price, place, promotion and negotiation so that growers could be better equipped in marketing skills.

\section{Acknowledgements}

First, thanks are to God for providingsound mind, good health and the opportunity to study. Secondly, I am grateful to my supervisors Dr. C.Ombuki and Dr. D.Mbogori for their ever timely advice. Their insightful comments helped immensely in shaping this thesis. However, I hasten to all that any shortcomings are solely mine. (I take responsibility for all the shortcomings). I am equally extending my gratitude to the MT. Kenya University for administrative assistance. Worthy mentioning too are the men and women who helped in typing, editing and printing this document. To all I return every bit of thanks. Finally, I salute the members of my family for moral, material and financial support.

\section{References}

Abd El-Razek, A. (2002). Peasants level knowledge related to environmental pollution resulting from chemical fertilizations and pesticides and its relationship to some variables in Babilonia Governorate, Iraq.

ABD/DANIDA. (2010). Eastern Province Mango census \& Baseline survey report.

Adesina, A. A., \& Baidu-Forson, J. (2005). Farmers' perceptions and adoption of new Agricultural Technology: Evidence from in Burkina Faso and Guinea, in Africa. Agricultural Economics, 13, 1-9. http://dx.doi.org/10.1016/0169-5150(95)01142-8 
Baidu-Forson, J. (2000). Factors influencing adoption of land-enhancing technology in the Sahel: Lessons From A case Study in Niger. Agricultural Economics, 20, 231-239. http://dx.doi.org/10.1016/S0169-5150(99)00009-2

Best Media Info Bureau. (2010). Coca Cola's New Innovation 'Maaza Milky Delite', Delhi. Bulletin, 621.

Bulale, A. I. (2000). Smallholder dairy production and dairy technology adoption in the mixed farming system in Arsi Highland, Ethiopia. Ph.D. Dissertation, Humboldt University of Berlin.

Caswell, M. K., Fuglie, C., Ingram., S. J., \& Kascak, C. (2001). Adoption of Agriculture production practices: Lessons learned from the US. Department of Agriculture area studies project. Washington DC. US Department of Agriculture. Resource Economics Division, Economic Research service, Agriculture Economic Report No.792.January.

Diederen, P. J. M., Van Meijl, J. C. M., \& Wolters, A. M. (2002). Innovation and farm performance: the case of Dutch agriculture. In Kleinknecht A., \& Mohnen, P. (Eds.), Innovation and Firm Performance: Econometric Explorations of Survey Data. London: Palgrave MacMillan.

Ejidiah, W. (2010). Mango New Innovation. Nairobi: ICIPE. Kenya.

El-Melegi, M. H. (2000). Farmers knowledge and implementation level of dairy cattle's breeding and management practices in El- Menoufia Governorate, Egypt. Res. Bull. No. 257, AERDRI, ARC, MALR.

Feder, G., \& Slade, R. (2004). The acquisition of information and the adoption of new Technology. American Journal of Agricultural Economics, 66, 312-320. American Agricultural Economics Association. http://dx.doi.org/10.2307/1240798

Gethun, D., W., Mawangi, H. V., \& Abdishekur, W. A. (2000). An assessment of the adoption seed and fertilizer packages and the role of credit in smallholder Maize in Sidama and North Oma Zones, Ethiopia. Mexico, D.F.: International Maize and Wheat Improvement Center (CIMMTY) and Ethiopian Agricultural Research Organization (EARO).

Horticulture Development Centre. (2008). Horticulture Marketing News. Nairobi: USAID.

Lemma, F., \& Trivedi, M. M. (2012). Extent of adoption of improved dairy husbandry practices in Ada'a district of Oromia state, Ethiopia. Wudpecker Journal of Agricultural Research, 1(6), 203-207.

Madhukar, C., \& Ram, C. (2012). Adoption of scientific dairy farming practices by Ex-Servicemen. Indian Journal of Dairy Science, 49(8), 507-510.

Ministry of Agriculture. (2000, 2010). Annual report. Nairobi, Kenya.

Moturi, M. C. Z., Ngunjiri, P. W., Otieno, D., \& Nyambane, B. (2010). Processing and technology infrastructure towards unearthing the gold in mango. KIRDI: National Mango Conference at Nairobi.

Msabeni, A., Muchai, D., Masinde, G., Mato, S., \& Gathara, V. (2010). Sweetening the Mango: Strenghtening the value chain. An analysis of the organizational linkages along the mango value chain. Mbeere District Eastern Province, Kenya.

Mussei, A., Mawanga, J., Mawangi, W., Verkuijl, H., Mngi, R., \& Langa, A. (2001). Adoption of improvement wheat technologies by small-scale farmers in Mbeya District, Southern Highlands, Tanzania. Mexico, D.F.: International Maize and Wheat Improvement Center (CIMMTY) and the United Republic of Tanzania.

Nchinda, V. P., \& Mendi, S. D. (2008). Factors influencing adoption of yoghurt technology in the western highlands agro ecological zone of Cameroon.

Republic of Kenya. (2008). Vision 2030. Government press. Nairobi.

Rezvanfar, A. (2007). Communication and socio-personal factors influencing adoption of dairy farming technologies amongst livestock farmers. Livestock Research for Rural Development, 19.

Salama, F. A. (2001). A path analysis of innovativeness of animal production innovations. Menoufia Journal of Agricultural Research, 26(1), 303-324. 